University of Nebraska - Lincoln

DigitalCommons@University of Nebraska - Lincoln

Faculty Publications: Department of Entomology

October 1984

\title{
Evaluation of Crop Rotation for Control of Colorado Potato Beetles (Coleoptera: Chrysomelidae) in Commercial Potato Fields on Long Island
}

Robert J. Wright

University of Nebraska-Lincoln, rwright2@unl.edu

Follow this and additional works at: https://digitalcommons.unl.edu/entomologyfacpub

Part of the Entomology Commons

Wright, Robert J., "Evaluation of Crop Rotation for Control of Colorado Potato Beetles (Coleoptera: Chrysomelidae) in Commercial Potato Fields on Long Island" (1984). Faculty Publications: Department of Entomology. 99.

https://digitalcommons.unl.edu/entomologyfacpub/99

This Article is brought to you for free and open access by the Entomology, Department of at DigitalCommons@University of Nebraska - Lincoln. It has been accepted for inclusion in Faculty Publications: Department of Entomology by an authorized administrator of DigitalCommons@University of Nebraska - Lincoln. 


\title{
Evaluation of Crop Rotation for Control of Colorado Potato Beetles (Coleoptera: Chrysomelidae) in Commercial Potato Fields on Long Island
}

\author{
ROBERT J. WRIGHT \\ Department of Entomology, Cornell University, \\ Long Island Horticultural Research Lab, 39 Sound Avenue, \\ Riverhead, New York 11901
}

\begin{abstract}
J. Econ. Entomol. 77: 1254-1259 (1984)
ABSTRACT Leptinotarsa decemlineata (Say) densities, potato defoliation levels, and grower insecticide use were monitored in commercial potato fields with differing rotational histories on Long Island, New York. Rotation for 1 year to a nonhost grain crop (rye or wheat) significantly reduced the pest status of $L$. decemlineata in the following year's potato crop. Early season (late May) adult densities were reduced $95.8 \%$ in three of four comparisons in 1982 and $69.5 \%$ in two of three comparisons in 1983. In one comparison each year, early season $L$. decemlineata densities were low in both the rotated and nonrotated fields due to past grower practices. Season-long (June-August) paired comparisons of rotated and nonrotated fields were conducted on four farms in 1982 and five farms in 1983. In these comparisons, growers used an average of one (range, 0-2) additional insecticide application for $L$. decemlineata control during the first generation on the nonrotated fields. Despite this, defoliation levels and $L$. decemlineata densities were higher in several cases in the nonrotated fields. The effect of crop rotation was greatest early in the season and was not detectable after the end of the first $L$. decemlineata larval generation on Long Island.
\end{abstract}

The Colorado potato beetle (CPB), Leptinotarsa decemlineata (Say), is the major insect pest of potatoes in much of the Northeast and mid-Atlantic regions of North America. Historically, insecticidal control has been the major tactic used against this insect (Gauthier et al. 1981). Insecticide resistance has been a continuing problem in CPB management, especially in the eastern United States (Hare 1980, Forgash 1981). Additionally, on Long Island, New York, pesticides used in potato production (e.g., aldicarb, carbofuran, and oxamyl) have contaminated groundwater and are no longer registered for use on Long Island.

Alternate control measures (e.g., cultural or biological control) are urgently needed to provide a more diverse strategy for CPB management in an environmentally sound fashion. Crop rotation is one cultural practice currently in use on Long Island that contributes to CPB control. The most common rotation crops on Long Island are grains, especially winter rye. Grains are seeded in the fall after harvest on most of the potato acreage as a cover crop to reduce wind and water erosion of soil and to increase soil organic matter. A common rotation consists of allowing this rye to grow into the following summer when it is harvested for grain and straw. Compared with potatoes, these are relatively low value crops and thus rotation is not practiced frequently.

Current research on Long Island is designed to identify alternate rotational crops compatible with potato production, which would be economically more competitive than grain crops such as rye. To provide information on the benefit that crop rotation provides in the present potato agroecosystem on Long Island, I studied commercial potato fields. I evaluated benefit in terms of CPB densities, potato defoliation, and grower insecticide usage. To my knowledge, this is the first published evaluation of crop rotation for control of CPB on potatoes.

\section{Materials and Methods}

All cooperating growers were participants in a pilot integrated pest management (IPM) program for potatoes on Long Island (Wright et al. 1983). Pairs of rotated and nonrotated fields were monitored on four farms in 1982 and five farms in 1983. Each pair of fields was located on the same farm to minimize differences between the two fields. Distance between the paired fields on each farm varied from 0 to $2 \mathrm{~km}$, but other potato fields on a farm may have been closer to the study fields. Nonrotated fields had been in potato production during the previous year, but may have been rotated out of potatoes in other years. All rotated fields had been out of potatoes for 1 year and the rotational crop was rye (except for one field of wheat in 1983). Field sizes averaged 8 ha (2-12 ha range) over the 2 years. In both years, all paired fields were planted to the same cultivar (either 'Superior' or 'Katahdin'), except for one case in 1983 in which a field planted with 'Hudson' was compared with a field planted with about half 'Hudson' and half 'Katahdin.' In both years, the 
two fields being compared were planted within 1 week of each other except for three farms in 1983, where the rotated fields were planted ca. 2 weeks before the nonrotated fields.

Adult CPB were sampled in both years in midto late May (after peak CPB emergence and after plant emergence but before any foliar insecticide sprays were applied). The number of adult CPB per $3 \mathrm{~m}$ of row was counted in 10 to 20 randomly chosen sites in each field. Soil-applied insecticides are not registered for use on potatoes on Long Island and were not used in any of the fields sampled.

Starting in early June, and continuing through August, weekly monitoring of CPB density (adults, egg masses, small [first and second instars] and large [third and fourth instars] larvae) and defoliation levels ${ }^{1}$ was conducted by the IPM program scouts. The sample unit was a single potato vine (stalk), as suggested by Harcourt (1963). Each vine was carefully examined and all CPB present were counted. In 1982, 80 vines were sampled per field on each visit; in 1983, 50 vines per field were sampled. In 1982, sampling was restricted to a ca. 4-ha section of each field, but in 1983, whole fields were sampled.

Data on pesticide use were requested from participating growers. The type and date of each insecticide treatment was recorded separately for each field. For comparing differences between pairs of fields on each farm, the number and timing of insecticide sprays (ignoring compounds) were used. Within a farm, this type of comparison is valid because growers generally applied similar treatments to both fields, but where differences occurred, the number and timing of insecticide sprays varied on different fields.

Early season adult CPB density data were transformed by $\log _{10}(x+1)$ before analysis as suggested by Harcourt (1963). Differences between pairs of fields on a farm were tested by a two-sample $t$ test from the MINITAB statistical program, with population variances not assumed to be equal and $P=$ 0.05 (Ryan et al. 1976). This program computes approximate degrees of freedom weighted by the sample variances and sample sizes of the two samples. Similar analyses were used on the data from season-long comparisons to compare CPB densities between pairs of fields on dates when peak densities of CPB life stages occurred. Data on defoliation levels were not analyzed statistically.

\section{Results and Discussion}

Effect of Rotation on Overwintered CPB Adults. In five of seven comparisons, early season (late May) CPB adult densities were significantly lower on rotated fields (Table 1). In these five comparisons, rotation resulted in a $95.8 \%(1982)$ or $69.5 \%$

${ }^{1}$ Defoliation index: $1=1-10 \% ; 2=11-25 \% ; 3=26-50 \%: 4=$ $51-90 \% ; 5=91-100 \%$.
Table 1. Effect of crop rotation on early season adult CPB densities in commercial potato fields, Long Island, N.Y., 1982-1983

\begin{tabular}{|c|c|c|c|}
\hline \multirow{3}{*}{ Grower no. } & \multirow{3}{*}{ Date } & \multirow{2}{*}{\multicolumn{2}{|c|}{$\frac{\mathrm{CPB} \text { adults } / 3 \text { row-m }}{\text { Field type }}$}} \\
\hline & & & \\
\hline & & $\mathbf{R}$ & NR \\
\hline \multicolumn{4}{|l|}{1982} \\
\hline 1 & 19 May & 0.15 & $3.1^{b}$ \\
\hline 2 & $19 \mathrm{May}$ & 0.04 & $1.6^{b}$ \\
\hline 3 & $21 \mathrm{May}$ & 0.23 & $4.4^{b}$ \\
\hline 9 & $18 \mathrm{May}$ & 0.28 & $0.32 \mathrm{NS}$ \\
\hline \multicolumn{4}{|l|}{1983} \\
\hline 6 & 25 May & 0.2 & $2.0^{b}$ \\
\hline 8 & $25 \mathrm{May}$ & 0.8 & $0.8 \mathrm{NS}$ \\
\hline 10 & 24 May & 5.4 & $10.6^{b}$ \\
\hline
\end{tabular}

${ }^{a} \mathrm{R}$, Rotated potato field; NR, nonrotated potato field.

${ }^{b} P<0.01$, Two-sample $t$ test, $\mathrm{df}=16-44$. NS, $P>0.05$.

(1983) reduction in early season CPB adult density. In one comparison each year, CPB densities were low in both the rotated and nonrotated fields (Table 1). Previous experience with these growers suggests that this was caused by routine use of insecticides on all fields throughout the previous growing season. Thus, rotation was always associated with low CPB densities. However, in some cases, nonrotated fields also had low CPB densities due to preventive use of insecticides by growers the previous year.

Early season data from only two (growers no. 6 and 8) of the five season-long comparisons for 1983 are shown in Table 1 . In the other three comparisons (growers no. 4, 5, and 7) during late May, potatoes had not emerged in the nonrotated fields because they had been planted 2 weeks later than the rotated fields. By the time the potatoes emerged, many CPB had emigrated elsewhere in search of food. Therefore, no comparisons were possible early in the season on these three farms. Data from grower no. 10 were available only early in the season, because these fields were not in the IPM program. Of the five early-season comparisons with significantly fewer CPB on rotated fields (Table 1), grower no. 10 had the least reduction from rotation. Both fields were small $(<1 \mathrm{ha})$ and were adjacent to each other. This suggests a minimum in field size and isolation for effective use of crop rotation for CPB control.

Season-Long Comparisons. Seasonal population dynamics of CPB, defoliation levels, and insecticide use for CPB control during 1982 for growers no. 1 through 3 are shown in Fig. 1. Data for grower no. 9 are not shown because there were no significant differences in CPB density, defoliation levels, or insecticide use between the rotated and nonrotated fields on this farm. There were no differences in insecticide usage on rotated and nonrotated fields during the first CPB generation (before 30 June) by growers no. 1 or 3 (Fig. 1). However, CPB densities of several stages were 

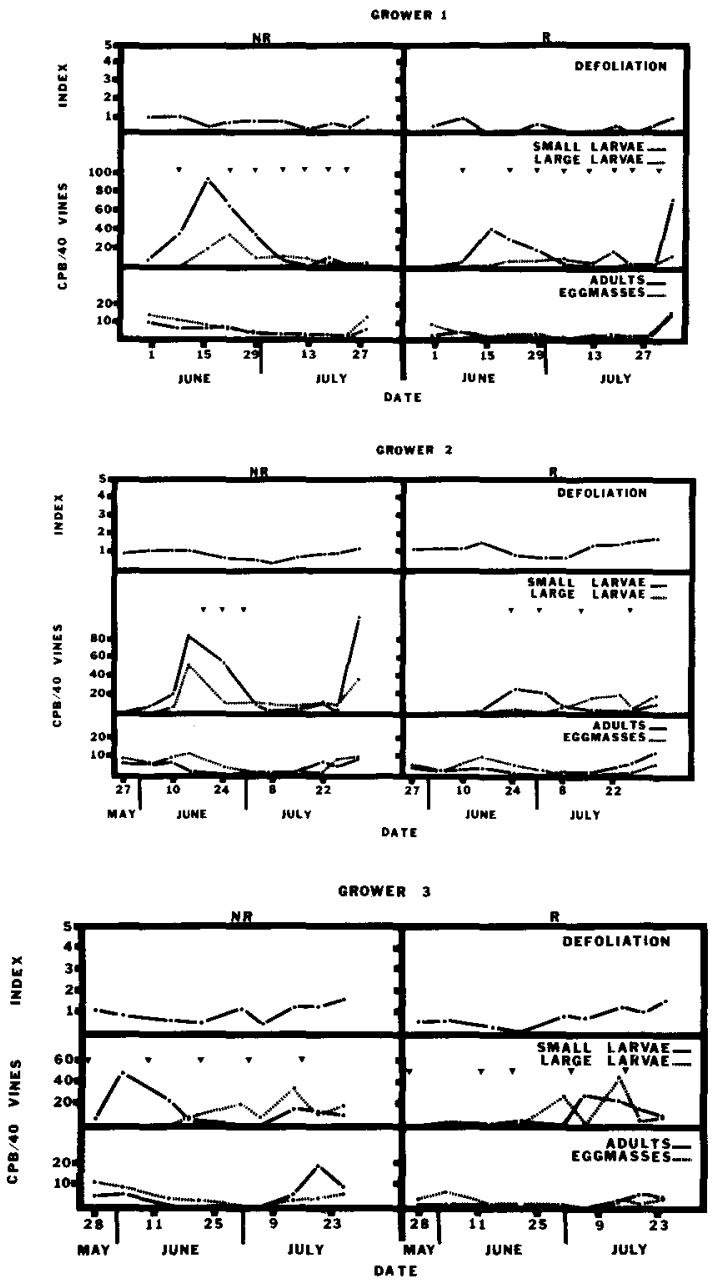

Fig. 1. Comparison of CPB densities, defoliation levels, and insecticide use in rotated and nonrotated potato fields on three commercial farms, Long Island, N.Y., 1982. NR, Nonrotated field; R, rotated field, $\mathbf{\nabla}, \mathrm{CPB}$ insecticide spray. See text for description of defoliation index.

higher on nonrotated fields during June (grower no. 1 , small larvae: $t=2.46, P<0.05$, $\mathrm{df}=37.8$; large larvae: $t=4.53, \mathrm{P}<0.01, \mathrm{df}=30.7$; grower no. 3 , adults: $t=2.32, P<0.05$, $\mathrm{df}=28.7$; small larvae: $t=2.11, P<0.05$, df $=23.1$ ). Grower no. 2 applied one additional insecticide spray during June on the nonrotated field (Fig. 1). Despite this, densities of small and large larvae were significantly greater on the nonrotated field during the first CPB larval generation (small larvae: $t=2.39$, $P<0.05, \mathrm{df}=34.4$; large larvae: $t=3.42, P<$ $0.01, \mathrm{df}=21.5$ ).

Seasonal population dynamics of CPB, defoliation levels, and insecticide usage for CPB control during 1983 for growers no. 4 through 7 are shown in Fig. 2. Data from the fifth comparison (grower no. 8) are not shown because there were no sig- nificant differences in CPB density, defoliation levels, or insecticide use between the rotated and nonrotated fields on this farm. Grower no. 4 needed two and grower no. 5 needed one additional insecticide sprays on the nonrotated fields to achieve densities of overwintered CPB adults equal to those that occurred on the rotated fields (Fig. 2). Despite the additional insecticide use, defoliation levels were much higher on the nonrotated field of grower no. 4 during June. Significantly more egg masses were found in the nonrotated fields in both comparisons (grower no. 4: $t=3.86$, $P<0.01, \mathrm{df}=13.8$; grower no. 5: $t=2.85, P<$ 0.01 , $\mathrm{df}=14.8$ ). However, there were no differences in densities of small or large larvae during June in either comparison. Growers no. 6 and 7 both applied two additional insecticide sprays to the nonrotated fields during June. Despite this, early season defoliation levels were higher on both nonrotated fields and grower no. 6 had significantly higher densities of CPB adults, egg masses and small larvae on the nonrotated field during the first CPB generation (adults: $t=2.83, P<0.05$, $\mathrm{df}=18.0$; egg masses: $t=4.36, P<0.01, \mathrm{df}=$ 16.3; small larvae: $t=2.97, P<0.01, \mathrm{df}=16.8$ ).

Thus, of nine on-farm comparisons over 2 years, there was no difference in insecticide use between the rotated and nonrotated field in May and June in four cases $(44.5 \%)$; in two cases $(22.2 \%)$, one additional insecticide application was made to the nonrotated field; in three cases (33.3\%), two additional insecticide sprays were applied to the nonrotated field. Therefore, on the average, one more insecticide spray was applied to the nonrotated fields during May and June for CPB control.

Although suggested action thresholds for CPB control were provided to growers along with weekly scouting reports on CPB density (Wright et al. 1983), grower use of insecticides did not always correspond to objectively defined need. Therefore, insecticide use by growers is an imperfect indication of CPB pest status. However, this study demonstrated a reduction in CPB pest status on rotated potato fields. In most cases, fewer insecticide sprays were needed to maintain CPB densities at nearly equivalent levels in rotated compared with nonrotated fields. Even with increased early season insecticide use, CPB density and defoliation levels were higher in some cases on nonrotated than on rotated fields (e.g., grower no. 6, Fig. 2) which suggests that even more insecticide sprays would have been needed on the nonrotated fields to provide equivalent $\mathrm{CPB}$ control. However, in other cases, additional late season sprays were applied unnecessarily to rotated fields (e.g., growers no. 1 and 2, Fig. 1), resulting in more insecticide sprays being applied to the rotated field over the whole growing season. This does not indicate greater CPB pest status on rotated fields. In evaluating the effect of crop rotation, differences in insecticide use early in the season (May and June) most accurately reflect CPB pest 

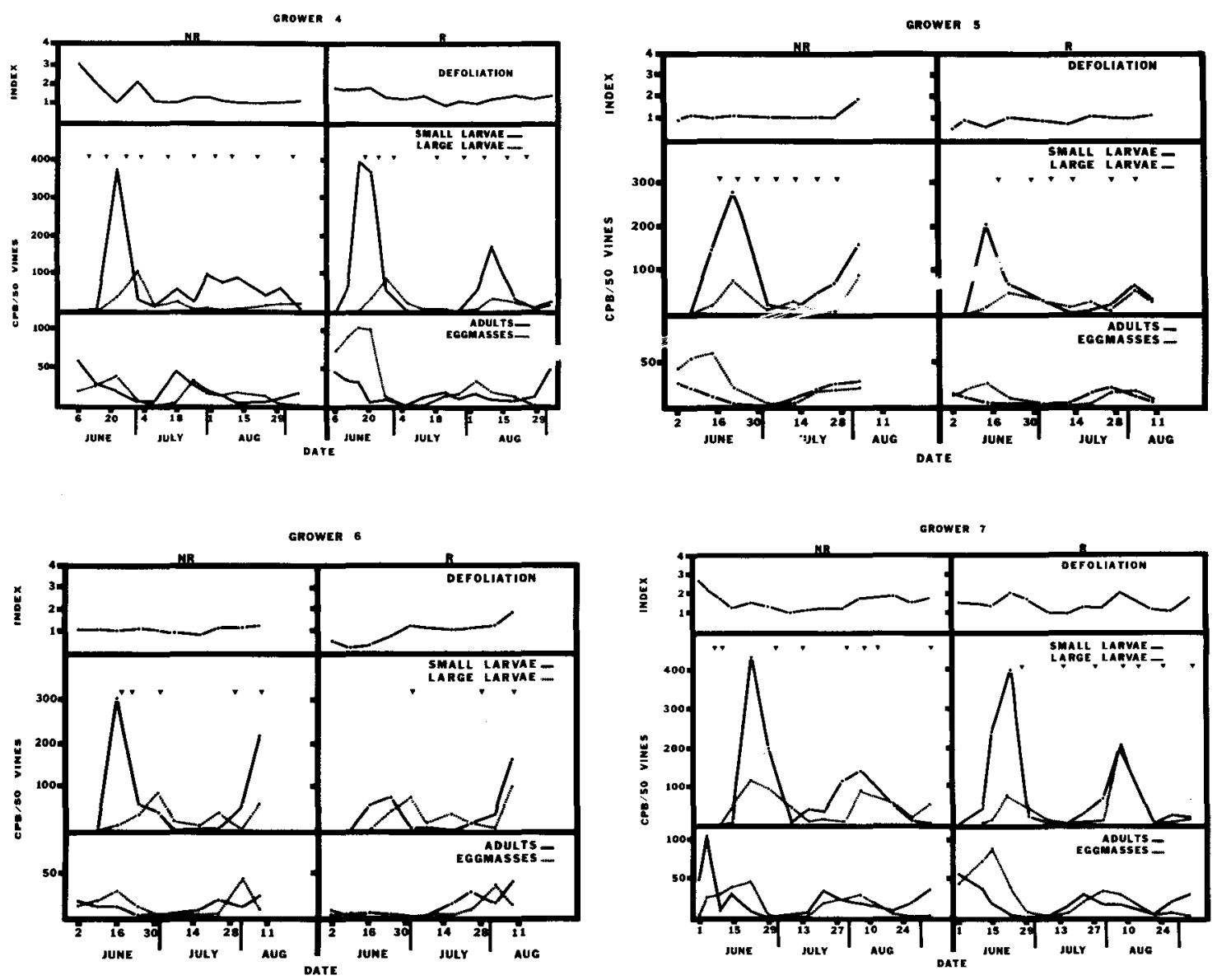

Fig. 2. Comparison of CPB densities, defoliation levels, and insecticide use in rotated and nonrotated potato fields on four commercial farms, Long Island, N.Y., 1983. Abbreviations, symbols, and defoliation index same as in Fig. 1.

status. As the season progresses, confounding effects from grower overuse of insecticides are more likely to occur.

Effect of Planting Date. As noted in Materials and Methods, three growers (no. 4, 5, and 7) in 1983 had a 2-week delay in planting on the nonrotated field compared with the rotated field. The later planting dates of these three nonrotated fields resulted in emergence of potato plants after many of the CPB adults had emerged. When this happened, CPB began to emigrate in search of food. Therefore, early season adult and egg mass densities (Fig. 2) may be somewhat reduced in these nonrotated fields and would tend to minimize the real effect (corrected for planting date effect) of crop rotation on CPB in these three comparisons.

Despite the fact that later planting may result in an apparent decrease in CPB density early in the season, this is not a recommended practice for $\mathrm{CPB}$ management on Long Island. The reduction is only seen on a single-field basis. On a larger scale within a farm, the emigrating CPB may merely move to a nearby field that was planted earlier.
Also, later-planted potatoes are of a smaller size when CPB begin feeding and a given amount of CPB feeding results in a greater percentage of defoliation than would occur on a larger plant. Therefore, early planting, in combination with crop rotation, is the best combination of cultural practices to reduce early season CPB damage.

Effects of Crop Rotation on CPB Biology. Generally, crop rotation is most effective for pest species with a narrow host range and limited powers of dispersal. The narrow host range of CPB in the Solanaceae is well documented (Hsiao 1981). However, CPB dispersal is less well studied. After spring emergence, overwintered CPB adults in the northeastern United States and south and central Europe disperse mainly by walking ( $\mathrm{Ng}$ and $\mathrm{La}-$ shomb 1983, Johnson 1969).

The observed differences in rotated and nonrotated fields could be due to several effects. The overwintering site of CPB is in or near the potato (or other host) field in which they developed (Gibson et al. 1925), although this has never been studied quantitatively. Thus, the initial density of CPB 
emerging in a rotated field should be greatly reduced in the spring. CPB emerging in the spring in a nonrotated field would have little trouble finding host plants (de Wilde 1976, May and Ahmad 1983) and would begin feeding and laying eggs. $\mathrm{CPB}$ emerging in the spring in an area not containing a host species will have to disperse in search of host plants. There may be mortality associated with this movement. Secondly, there will be a time lag involved in dispersing from the emergence site and finding a host plant. From the point of view of CPB population dynamics within a rotated field, this might result in a delayed population buildup compared with CPB in nonrotated fields. All these factors could be responsible for patterns such as seen in Table 1 and in Fig. 1 and 2.

The fact that the effect of crop rotation is not season-long (Fig. 1 and 2) could be due to several factors. In the absence of insecticides, even low initial densities of CPB in rotated fields will be able to produce damaging populations, given the high potential fecundity of CPB (Brown et al. 1980). Also, immigration of CPB from adjacent fields could increase CPB densities in rotated fields. The relative importance of these two factors is not known. Finally, the observation that differences between rotated and nonrotated fields largely disappear at the end of the first larval CPB generation could be related to the fact that the adults which emerge in July are much more likely to disperse by flight (Johnson 1969, de Wilde and Hsiao 1981), which would tend to equalize CPB densities between rotated and nonrotated fields.

The degree of isolation of the study fields was not quantified, but could have an influence on the results observed in this study. On Long Island, crop rotation is not practiced frequently, potato production is concentrated in a few areas, and alternate host species of CPB (e.g., eggplant, tomatoes, or solanaceous weeds) are produced on very limited acreage. Where rotation is practiced, a CPB nonhost is grown every third or fourth year. Rotation in other areas with different cropping systems or more frequent crop rotation may not see as great a difference, in relative terms, between rotated and nonrotated fields.

Use of Crop Rotation in Potato IPM. In some IPM programs, crop rotation is a major tactic for management of insect pests (e.g., corn rootworms in corn [Luckmann 1978]). In potatoes, however, crop rotation provides only partial control of CPB. As demonstrated in this paper, the greatest effect of crop rotation on CPB is against the overwintered adults and their progeny in May and June.

On Long Island, the use of soil-applied insecticide/nematicides has been eliminated and early season CPB control has become more difficult. CPB adults emerge in the spring around the time that potatoes are emerging in many fields (unpublished data). High CPB densities, such as those occurring on nonrotated fields early in the season, often result in severe defoliation and delayed growth of emerging potato plants. Crop rotation and other cultural control practices (e.g., early planting) are important IPM tactics, because they provide partial control of CPB in May and June. Although it is likely that rotation on an areawide basis would have a greater impact on CPB populations, this study has demonstrated that rotations of 1 year out of potatoes in the concentrated potato production regions of Long Island provides useful levels of pest reduction. Greater use of crop rotation and other cultural control practices would decrease the dependence of Long Island potato growers on frequent applications of foliar insecticides for early season CPB control.

Crop rotation has effects on other potato pests. Certain rotational crops, such as grain, are generally good hosts for the root lesion nematode, Pratylenchus penetrans (Mai et al. 1977). If soil $\mathrm{pH}$ is raised to accommodate certain crops in a potato rotation, the severity of common scab of potatoes, caused by Streptomyces scabies, may be increased (Thurston 1978). These and other potential effects should be considered in the use of crop rotation in potato IPM programs.

\section{Acknowledgment}

I thank E. Deaton, D. Kain, L. Urevich, and M. Werner for data collection, the cooperating growers for their participation in the Long Island potato IPM pilot program and D. Kain for assistance in data analysis and manuscript preparation. I also thank J. W. Van Duyn (North Carolina State Univ., Raleigh) and R. Loria and M. J. Tauber (Cornell Univ., Ithaca) for reviewing an earlier draft of this manuscript. The Office of Research, New York State College of Agric. and Life Sciences, Cornell Univ., provided partial financial support for this project.

\section{References Cited}

Brown, J. J., T. Jermy, and B. A. Butt. 1980. The influence of an alternate host plant on the fecundity of the Colorado potato beetle, Leptinotarsa decemlineata (Coleoptera: Chrysomelidae). Ann. Entomol. Soc. Am. 73: 197-199.

Forgash, A. J. 1981. Insecticide resistance of the Colorado potato beetle, Leptinotarsa decemlineata (Say), pp. 34-46. In J. H. Lashomb and R. Casagrande [eds.], Advances in potato pest management. Hutchinson Ross Publishing Co., Stroudsburg, Pa.

Gauthier, N. L., R. N. Hofmaster, and M. Semel. 1981. History of Colorado potato beetle control, pp. 13-33. Ibid.

Gibson, A., R. P. Corham, H. F. Hudson, and J. A. Flock. 1925. The Colorado potato beetle in Canada. Dom. Can. Dept. Agric. Bull. No. 52.

Harcourt, D. G. 1963. Population dynamics of Leptinotarsa decemlineata (Say) in Eastern Ontario. I. Spatial pattern and transformation of field counts. Can. Entomol. 95: 813-820.

Hare, J. D. 1980. Contact toxicities of ten insecticides to Connecticut populations of the Colorado potato beetle. J. Econ. Entomol. 73: 230-231. 
Hsiao, T. 1981. Ecophysiological adaptations among geographic populations of the Colorado potato beetle in North America, pp. 69-85. In J. H. Lashomb and R. Casagrande [eds.], Advances in potato pest management. Hutchinson Ross Publishing Co., Stroudsburg, $\mathrm{Pa}$.

Johnson, C. G. 1969. Migration and dispersal of insects by flight. Methuen, London.

Luckmann, W. H. 1978. Insect control in corn-practices and prospects, pp. 137-156. In E. H. Smith and D. Pimentel [eds.], Pest control strategies. Academic Press, New York.

Mai, W. F., J. R. Bloom, and T. A. Chen. 1977. Biology and ecology of the plant-parasitic nematode, Pratylenchus penetrans. Penna. State Univ. Agric. Exp. Stn. Bull. 815.

May, M. L., and S. Ahmad. 1983. Host location in the Colorado potato beetle: searching mechanisms in relation to oligophagy, pp. 173-200, In S. Ahmad [ed.], Herbivorous insects: host-seeking behavior and mechanisms. Academic Press, New York.

Ng, Y.-S., and J. Lashomb. 1983. Orientation by the Colorado potato beetle (Leptinotarsa decemlineata Say). Anim. Beh. 31: 617-620.
Ryan, T. A., Jr., B. L. Joiner, and B. A. Ryan. 1976. Minitab student handbook. Duxburg Press, North Scituate, Mass.

Thurston, H. D. 1978. Potentialities for pest management in potatoes, pp. 117-136. In E. H. Smith and D. Pimentel [eds.], Pest control strategies. Academic Press, New York.

de Wilde, J. 1976. The olfactory component in hostplant selection in the adult Colorado beetle (Leptinotarsa decemlineata Say). Symp. Biol. Hung. 16: 291-300.

de Wilde, J., and T. Hsiao. 1981. Geographic diversity of the Colorado potato beetle and its infestation in Eurasia, pp. 47-68. In J. H. Lashomb and R. Casagrande [eds.], Advances in potato pest management. Hutchinson Ross Publishing Co., Stroudsburg, Pa.

Wright, R. J., R. Loria, J. B. Sieczka, and D. D. Moyer. 1983. Final report of the 1982 Long Island potato integrated pest management pilot program. Vegetable Crops Mimeo 287, Long Island Horticultural Research Lab, Riverhead, N.Y.

Received for publication 2 April 1984; accepted 23 May 1984. 